\title{
Plasma carotenoid levels in passerines are related to infection by (some) parasites
}

\section{Jordi Figuerola *, Guillermo López and Ramón Soriguer}

Estación Biológica de Doñana - CSIC, Sevilla, Spain

\section{Edited by:}

Geoffrey E. Hill, Auburn University, USA

\section{Reviewed by:}

Miguel Moreno-García, Instituto Nacional de Salud Pública (National Institute of Public Health), Mexico Fernando Mateos-Gonzalez, Uppsala University, Sweden

\section{*Correspondence}

Jordi Figuerola, Estación Biológica de Doñana, Avda. Américo Vespucio $s / n, 41092$ Sevilla, Spain e-mail: jordi@ebd.csic.es
Plumage coloration plays an important role in intra and inter-sexual competition in birds. Many of the yellow, orange, or red colors present in birds are carotenoid dependent. Carotenoids cannot be synthetized de novo by birds and consequently should be obtained through their diet, and access to carotenoids may differ between individuals and species. In addition to ornamentation, carotenoids are important for bird physiology and it has been proposed that a trade-off in their allocation to these two functions occurs. Under this scenario parasites may play a central role in maintaining the honesty of plumage as a signaling system by increasing the demands for carotenoids for infection or damage control and/or by reducing carotenoid absorption in the intestines. We analyzed the relationship between (1) carotenoid concentrations in plasma and (2) blood and intestinal parasite richness and abundance in 22 species of passerines sampled in spring. Loads of different groups of parasites were unrelated so conclusions drawn from examining a particular group of parasites cannot be extrapolated to the whole community of pathogens and parasites inhabiting a host. At intraspecific level plasma carotenoid concentration was negatively related to the richness of intestinal parasites and the abundance of some groups of intestinal parasites, at interspecific level plasma carotenoid concentration was negatively related with the abundance of intestinal parasites. No relationship at intra- nor interspecific level was found between carotenoids and blood parasites. The results suggest that intestinal parasites play an important role in the evolution and maintenance of carotenoid-derived sexually selected ornamentations probably through a negative impact on the uptake of carotenoids at the gut.

Keywords: blood parasites, endoparasites, host-parasite interactions, plumage coloration, sexual selection
Hamilton and Zuk (1982) proposed that plumage coloration in birds may act as a reliable indicator of resistance to parasites. Most comparative analyses have supported this hypothesis by reporting a relationship between parasite prevalence or richness and interspecific differences in plumage coloration (e.g., Scheuerlein and Ricklefs, 2004 and references therein). At intraspecific level, positive, negative, and non-significant relationships between parasitism and plumage coloration have been reported (Hill, 2006). However, experiments performed up to now largely support the idea of a negative impact of ectoparasites (Figuerola et al., 2003) and coccidian endoparasites (Brawner et al., 2000; McGraw and Hill, 2000; Hõrak et al., 2004) on plumage coloration. Many of the colorations involved in sexual selection are derived from carotenoids (Badyaev and Hill, 2000), pigments that cannot be synthesized by birds and thus have to be incorporated from their diets (Olson and Owens, 1998). Consequently, dietary access to carotenoids may strongly limit the development of carotenoid derived colorations (Hill, 2006). Carotenoid derived coloration has been associated with nutritional status and condition of the individuals (Hill and McGraw, 2006), efficiency of vital cellular processes (Hill and Johnson, 2012), cognitive function (MateosGonzalez et al., 2011) or escape behavior (Mateos-Gonzalez et al., 2014). Interestingly, carotenoids are not only used to confer color on feathers and skins, but are also involved in the synthesis of different vitamins and the control of oxidative stress (von Schantz et al., 1999; Blas et al., 2006 but see Constantini and Møller, 2008). A recent meta-analysis concluded that carotenoid levels in birds are related to individual immune response and antioxidant capacity (Simons et al., 2012). For example, the inflammatory/immune response elicited by the injection of a vegetal protein (PHA test) is associated to a decrease in the levels of carotenoids in blood (Biard et al., 2009). However, it is unclear if carotenoids act properly as antioxidants or just are affected by organisms antioxidant status (Simons et al., 2012). For these reasons, it has been proposed that birds have to face a trade-off between investing carotenoids in showiness or in health-related functions (von Schantz et al., 1999; Peters, 2007). Under this scenario, parasites and pathogens may play a central role in the regulation of the honesty of birds' signaling systems. The mechanistic and physiological processes linking parasites, health and ornament expression are now the focus of intense debate and research.

Concentrations of carotenoids differ widely between individuals; individuals with higher concentrations of carotenoids in their blood usually develop brighter plumages (Figuerola et al., 1999; Yang et al., 2013) and have a more active immune system (Blas et al., 2006; Aguilera and Amat, 2007). Studies of interspecific 
variation in carotenoids levels are less common. Tella et al. (2004) analyzed some ecological, morphological, and evolutionary factors related to variations in carotenoid concentrations in the blood of 80 wild bird species. Phylogeny, body size, and the presence of carotenoid-dependent colorations were related to interspecific differences in carotenoids. Concentration of carotenoids varied allometrically with body mass in nine species of raptors, once controlling for differences in diet (Blanco et al., 2014). Although Tella et al. (2004) have already suggested that some of the interspecific variation they found in carotenoid concentrations in plasma may merely reflect differences in the incidence of coccidian parasites between species, to our knowledge no study has ever analyzed the relationship between parasitism and interspecific variation in the circulation of carotenoids. At intraspecific level, Mártinez-Padilla et al. (2007) reported an increase in the concentration of carotenoids in the blood after experimentally reducing infection by nematodes in Red Grouse (Lagopus lagopus), while the reduction of coccidian loads has been reported to lead to increased plasma carotenoid levels in Greenfinches (Carduelis chloris) and growing chickens (Zhu et al., 2000; Hõrak et al., 2004; Pap et al., 2011).

In this paper, we analyze the relationship of carotenoids and parasitism in 22 species of passerines in terms of two different groups of parasites: haematozoa and intestinal parasites. First of all we tested the relationship between the incidence of different parasite groups and the levels of plasma carotenoids in individual birds. Secondly, we tested the role of interspecific differences in the incidence of parasitism as a means of explaining interspecific differences in the concentration of plasma carotenoids. Overall, we provide evidence that levels of circulating carotenoids are negatively related to the loads of some endoparasites, notably those that may negatively affect carotenoid uptake at the intestine.

\section{METHODS}

We captured 354 individuals of 22 passerine species (Table 1) during the pre-breeding migration period (March-May) in 2004 and 2005 in a tree nursery in a suburb of the Spanish city of Seville

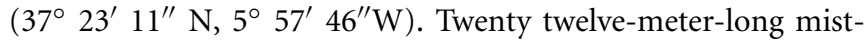
nets were operated from sunrise to sunset. Between capture and ringing birds were kept individually in clean cloth bags to allow any droppings produced during this time to be collected. Each bird was marked with a numbered ring and wing length (to the nearest $\mathrm{mm}$ ) and body mass (to the nearest $0.1 \mathrm{~g}$ ) were measured. Whenever possible sex was determined on the basis of the plumage characteristics given by Svensson (1996). Subsequently, $0.5 \mathrm{ml}$ of blood was taken from the birds' jugular vein using $29 \mathrm{G}$ sterile insulin syringes. A drop of this blood was used to prepare a smear on a microscopic slide (as per Bennett, 1970), which was air dried and then fixed and stained using Diff-Quick solution. The rest of the blood sample was placed in a vial and after several hours centrifuged for $10 \mathrm{~min}$ at $6000 \mathrm{rpm}$ in an Eppendorf Minispin centrifuge to separate serum from cells. Samples were then stored at $-20^{\circ} \mathrm{C}$ to be used for other studies (see López et al., 2008). After blood extraction, birds were kept individually in the cloth bags for $20 \mathrm{~min}$ to collect fecal samples and were then released. Between 0.5 and $1 \mathrm{mg}$ of feces were placed in individually marked vials containing 5\% formaldehyde and the collection time was annotated for each sample.

Ringing procedures were approved by the Spanish Ministry of Environment according to Ley 8/2003 (permit number 530394). Blood samples were taken with authorization of the Spanish Ministry of Environment (permit number 39/2003). All efforts were made to minimize suffering during handling and sample collecting, and birds were released in less than $30 \mathrm{~min}$ after their capture. According to Spanish law in 2004-2005, no approval by Animal Care and Use Committee was needed for this field study (Ley 8/2003).

\section{LABORATORY METHOD}

Blood smears were scanned for blood parasites at low $(400 \times)$ and high (oil $1000 \times$ ) magnification: a total of 15,000 erythrocytes were explored in each sample (Godfrey et al., 1987). Parasites were identified to genera level and when intraerythrocytic parasitemia occurred, the blood parasite load was estimated as the percentage of infected erythrocytes. Haemoproteus spp. (27.7\% prevalence), Plasmodium spp. (16.4\%), Leucocytozoon spp. (6.2\%), and Trypanosoma spp. $(0.8 \%)$ were detected in the blood slides (Table 1).

Droppings were filtered through a double layer of cotton-lint cheesecloth and scanned for endoparasites in a McMaster chamber. A known volume of the sample was dried and the dry weight of the feces was used to estimate the number of oocysts or eggs per mg of dry feces (following López et al., 2007). The most frequent parasite species found were Protozoan coccidia of the genera Isospora ( $45.5 \%$ prevalence), although some trematodes and nematodes were also found. Taxonomic identifications of blood and intestinal parasites were done according to Carpenter (1996). Because most species could not be identified, parasites were grouped according to Order: Trematoda: Strigeida (3.1\%); Nematoda: Spirurida (13.6\%), Capilariida (4.8\%), Ascarida (3.4\%) and unidentified nematodes (6.2\%, Table 1). All screening of the samples was carried out by one of the authors (GL).

\section{MOLECULAR SEXING}

The cellular fraction of the blood sample was used to extract DNA for each bird and sex was determined using a polymerase chain reaction (PCR) amplification of the CHD genes with the P2/P8 primers following the PCR conditions given by Ellegren (1996) and Griffiths et al. (1998).

\section{CAROTENOID OUANTIFICATION}

Pigments were extracted from plasma by adding acetone to the plasma samples at a ratio of 1:1 $(v / v)$. The mixture was centrifuged at $13000 \mathrm{r} / \mathrm{min}$ at $16249 \mathrm{~g}$ for $10 \mathrm{~min}$ to precipitate the flocculant proteins (Negro and Garrido-Fernandez, 2000). The supernatant was retained and stored at $-20^{\circ} \mathrm{C}$ until highperformance liquid chromatography (HPLC) analysis. A Jasco PU-2089 Plus instrument equipped with a quaternary pump (Jasco Analítica Spain, S.L., Madrid) was used for carotenoid analyses, with a reverse-phase C18 column (Phenomenex Synergi $4 \mu$ ) and a pre-column of the same material with a particle size of $5 \mu \mathrm{m}$. Samples were prefiltered using an OEM nylon filter, $\left.0.45 \mu \mathrm{m}^{\circ}-4 \mathrm{~mm}\right)$ and later injected using a Rheodyne $7725 \mathrm{i}$ 
Table 1 | (A) Number of analyzed individuals per species (males/females), abundance of the different intestinal parasite groups (for each parasite the mean abundance, the maximum abundance and the number of infected individuals is given), (B) Abundance of the different blood parasite groups (for each parasite the mean abundance, the maximum abundance and the number of infected individuals is given except for extra-erythrocytic blood parasites, for whom only the number of infected individuals is given), parasite richness (mean number of different parasite groups and range in brackets) and caratoneid concentrations (mean and range in brackets).

\begin{tabular}{|c|c|c|c|c|c|c|c|c|c|c|c|}
\hline \multirow{2}{*}{$\begin{array}{l}\text { A } \\
\text { Host especie }\end{array}$} & \multicolumn{11}{|c|}{ Intestinal parasites } \\
\hline & $N$ & \multicolumn{2}{|c|}{ Coccidia } & \multicolumn{2}{|c|}{ Spirurida } & \multicolumn{2}{|c|}{ Capilarida } & \multicolumn{2}{|c|}{ Ascarida } & Und. nemates & Strigeida \\
\hline Acrocephalus scirpaceus & $12 / 6$ & \multicolumn{2}{|c|}{$66.17(823.45,5)$} & \multicolumn{2}{|c|}{$1(8.66,4)$} & \multicolumn{2}{|c|}{$0(0.09,1)$} & \multicolumn{2}{|c|}{$0.23(4.08,1)$} & $0.76(9.24,2)$ & $0.29(4.96,2)$ \\
\hline Carduelis carduelis & $18 / 2$ & \multicolumn{2}{|c|}{$680.21(4025,14)$} & \multicolumn{2}{|c|}{$0(0,0)$} & \multicolumn{2}{|c|}{$0(0,0)$} & \multicolumn{2}{|c|}{$0(0,0)$} & $0(0,0)$ & $0(0,0)$ \\
\hline Carduelis chloris & $12 / 9$ & \multicolumn{2}{|c|}{$196.42(1722.32,13)$} & \multicolumn{2}{|c|}{$0(0,0)$} & 010 & & & $0,0)$ & $0(0,0)$ & $0(0,0)$ \\
\hline Erithacus rubecula & $7 / 13$ & 28.47 & $.77,9)$ & $7.93(9$ & $4,4)$ & 7.0918 & $08,2)$ & & $0,0)$ & $1.18(23.69,1)$ & $3.9(78.07,1)$ \\
\hline Ficedula hypoleuca & $12 / 7$ & 12.55 & $7,5)$ & $0.52(3$ & & $4.51(85$ & $7,1)$ & 4.9 & $93.91,1)$ & $4.35(59.72,2)$ & $0(0,0)$ \\
\hline Hippolais pallida & $5 / 6$ & 16.11 & $25,4)$ & $5.3(5$ & $7,2)$ & 010 & & 3.2 & $35.98,1)$ & $0(0,0)$ & $0.39(4.34,1)$ \\
\hline Hippolais polyglotta & $7 / 2$ & 26.27 & $97,2)$ & $0.23(2$ & 1) & 0.4514 & $4,1)$ & 0.4 & $4.32,1)$ & $0.41(3.71,1)$ & $0(0,0)$ \\
\hline Lanius senator & $9 / 6$ & 78.66 & $84,7)$ & $0.71(7$ & 3) & 10.95 & $16,3)$ & & $0,0)$ & $0.28(4.27,1)$ & $0.47(7.05,1)$ \\
\hline Luscinia megarhynchos & $13 / 6$ & 60.02 & $86,6)$ & $13.24(9$ & , 5) & 0.4819 & 1, 1) & & $0,0)$ & $0.1(1.85,1)$ & $0(0,0)$ \\
\hline Parus major & $4 / 1$ & 698.64 & $8.99,4)$ & $1.25(3$ & 2) & 010 & & 0.4 & $2.42,1)$ & $0.11(2.51,2)$ & $0(0,0)$ \\
\hline Passer domesticus & $16 / 4$ & 280.62 & $.83,13)$ & $0.1(2$ & & 010 & & 0.4 & $.13,1)$ & $0.66(9.23,2)$ & $0(0,0)$ \\
\hline Passer montanus & $10 / 6$ & 295.89 & $1.42,8)$ & 010 & & 010 & & & $0,0)$ & $0(0,0)$ & $0(0,0)$ \\
\hline Phoenicurus phoenicurus & $7 / 1$ & 39.99 & $.49,3)$ & $1.33(6$ & & 0.8616 & $9,1)$ & 0.3 & $2.49,1)$ & $1.89(51.6,2)$ & $0.51(4.09,1)$ \\
\hline Phylloscopus bonelli & $2 / 3$ & & & $5.61(2$ & $6,1)$ & $6.31(31$ & $34,1)$ & & $0,0)$ & $0(0,0)$ & $0(0,0)$ \\
\hline Phylloscopus collybita & $6 / 5$ & 43.1 & $68,5)$ & $7.53(8$ & $4,1)$ & 010 & & & $0,0)$ & $0.66(1.29,1)$ & $0(0,0)$ \\
\hline Phylloscopus trochilus & $7 / 2$ & 1.49 & , 3) & $10.11(5$ & 1, 2) & 010 & & 0.6 & $5.13,1)$ & $0(0,0)$ & $8.32(61.5,2)$ \\
\hline Serinus serinus & $43 / 8$ & 185.11 & $00,25)$ & 010 & & $0<0$ & & & , 0) & $0(0,0)$ & $0(0,0)$ \\
\hline Sturnus unicolor & $4 / 3$ & 5412.35 & $46.19,1)$ & 16.64 (9 & 9, 3) & 9.62161 & $32,1)$ & & $0,0)$ & $5.18(36.26,1)$ & $0(0,0)$ \\
\hline Sylvia atricapilla & $8 / 11$ & 1.16 & 41, 4) & 12.31 & , 5) & $6.62(1$ & $53,3)$ & 1.1 & $10,3)$ & $3.02(38.99,2)$ & $0(0,0)$ \\
\hline Sylvia borin & $13 / 5$ & 13.98 & $33,4)$ & 2.9314 & 1, 3) & 010 & & & $0,0)$ & $0.11(2,1)$ & $0(0,0)$ \\
\hline Turdus merula & $16 / 8$ & 433.4 & $9.09,14)$ & $0.71(1$ & $2,2)$ & 010 & & 1.2 & $30.44,1)$ & $2.62(61.45,2)$ & $0.35(6.61,2)$ \\
\hline Turdus philomelos & $1 / 8$ & 3089.43 & $05.88,6)$ & 14.9518 & 3, 3) & $1.61(50$ & $59,2)$ & & $0,0)$ & $6.24(56.13,1)$ & $1.66(14.94,1)$ \\
\hline B & & & & od parasi & & & & & & Richness & \\
\hline Host especie ( $\mu \mathrm{g} / \mathrm{ml})$ & Pla & nodium & Haem & roteus & Leu* & Try $^{+}$ & & & Intestinal & All & Carotenoids \\
\hline Acrocephalus scirpaceus & 0.0014 & $013,2)$ & 0.0063 & $4,6)$ & 3 & 1 & 0.67 & $-2)$ & $0.83(0-3)$ & $1.50(0-4)$ & $26.5(6.0-49.6)$ \\
\hline Carduelis carduelis & 0.0059 & $.04,4)$ & 0.0897 & $826,12)$ & 0 & 0 & 0.80 & $-2)$ & $0.70(0-1)$ & $1.50(0-2)$ & 143.2 (14.9-325.0) \\
\hline Carduelis chloris & 0.0272 & $.546,2)$ & 0.0225 & $4,5)$ & 0 & 0 & 0.33 & $-2)$ & $0.62(0-1)$ & $0.95(0-3)$ & $51.7(1.6-149.4)$ \\
\hline Erithacus rubecula & 0.0122 & $.067,5)$ & 0.0507 & $6,2)$ & 3 & 0 & 0.50 & $-2)$ & $0.85(0-3)$ & $1.35(0-3)$ & $18.6(4.3-60.3)$ \\
\hline Ficedula hypoleuca & 0.0055 & $.046,5)$ & 0.09931 & $8,4)$ & 2 & 0 & 0.58 & $-2)$ & $0.68(0-2)$ & $1.26(0-3)$ & $7.2(1.1-13.8)$ \\
\hline Hippolais pallida & 0.0024 & $.02,2)$ & 1.3117( & $83,8)$ & 0 & 0 & 0.91 & $-2)$ & $0.73(0-3)$ & $1.64(0-5)$ & $24.2(3.6-84.9)$ \\
\hline Hippolais polyglotta & 0.2667 & $4,1)$ & 1.4449 & $32,8)$ & 1 & 1 & 1.22 & $-2)$ & $0.67(0-2)$ & $1.89(0-4)$ & $37.8(10.2-89.5)$ \\
\hline Lanius senator & 0.1467 & $.6,7)$ & 2.1841 & $35,11)$ & 5 & 1 & 1.60 & $-3)$ & $1.00(0-3)$ & $2.60(0-6)$ & $27.2(10.3-43.0)$ \\
\hline Luscinia megarhynchos & 0.0468 & $.633,4)$ & 0.09811 & $4,10)$ & 1 & 0 & 0.79 & $-2)$ & $0.68(0-2)$ & $1.47(0-4)$ & $13.0(0.9-32.0)$ \\
\hline Parus major & 0.0012 & $.006,1)$ & 01 & & 0 & 0 & 0.20 & $-1)$ & $1.80(1-3)$ & $2.00(0-3)$ & $59.5(15.2-80.0)$ \\
\hline Passer domesticus & 0.0047 & $.04,3)$ & 0.0003 & $006,1)$ & 0 & 0 & 0.20 & $-1)$ & $0.85(0-2)$ & $1.05(0-2)$ & $20.7(1.5-48.9)$ \\
\hline Passer montanus & 0.0081 & $.13,1)$ & 0.0004 & $006,1)$ & 3 & 0 & 0.31 & $-1)$ & $0.50(0-1)$ & $0.81(0-2)$ & $16.5(2.2-30.0)$ \\
\hline Phoenicurus phoenicurus & 0.0141 & $1,2)$ & 01 & & 0 & 0 & 0.25 & $-1)$ & $1.25(0-2)$ & $1.50(0-3)$ & $26.1(10.2-51.3)$ \\
\hline Phylloscopus bonelli & 0.115 & $.815,1)$ & 0.531 & $63,2)$ & 0 & 0 & 0.60 & $-2)$ & $0.40(0-1)$ & $1.00(0-2)$ & $11.1(3.9-51.0)$ \\
\hline Phylloscopus collybita & & , 0) & 0.0018 & $02,1)$ & 0 & 0 & 0.09 & $-1)$ & $0.64(0-2)$ & $0.13(0-3)$ & $42.9(3.5-95)$ \\
\hline Phylloscopus trochilus & 0.0014 & $.013,1)$ & 01 & & 1 & 0 & 0.22 & $-1)$ & $0.89(0-2)$ & $1.11(0-3)$ & $51.1(9.9-128.9)$ \\
\hline Serinus serinus & 0.0022 & $.0533,3)$ & 0.0012 & $.0333,3)$ & 0 & 0 & 0.12 & $-2)$ & $0.49(0-1)$ & $0.61(0-3)$ & $11.4(10.3-195.9)$ \\
\hline Sturnus unicolor & 0.09 & $63,1)$ & 0.0019 & $13,1)$ & 0 & 0 & 0.29 & $-1)$ & $1.11(1-3)$ & $2.00(0-4)$ & $15.0(1.4-21.3)$ \\
\hline Sylvia atricapilla & 0.0119 & $.181,2)$ & 0.0015 & $013,3)$ & 0 & 0 & 0.26 & $-1)$ & $0.89(0-3)$ & $1.16(0-3)$ & $41.6(2.6-195.4)$ \\
\hline Sylvia borin & 0.0001 & $.013,1)$ & 0.2145 & $133,10)$ & 1 & 0 & 0.61 & $-2)$ & $0.44(0-1)$ & $1.11(0-3)$ & $20.4(1.1-11.9)$ \\
\hline Turdus merula & 0.0183 & $24,6)$ & 0.2098 & $33,9)$ & 0 & 0 & 0.63 & $-2)$ & $0.88(0-2)$ & $1.50(0-3)$ & $22.3(4.1-58.1)$ \\
\hline Turdus philomelos & 0.0126 & $.04,4)$ & 0.0051 & $046,1)$ & 2 & 0 & 0.18 & $-2)$ & $1.44(0-3)$ & $2.22(0-4)$ & $24.5(12.8-52.3)$ \\
\hline
\end{tabular}

*Leucocytozoon, + Trypanosoma. 
valve equipped with a $20-\mu \mathrm{L}$ loop (Rheodyne, Rohnent Park, California, USA). The eluent system is that described in MínguezMosquera and Hornero-Méndez (1993), with the only difference being that the flow rate was $1 \mathrm{~mL} \cdot \mathrm{min}^{-1}$. Data were acquired between 195 and $650 \mathrm{~nm}$ with a multiwavelength detector (MD2010 Plus, Jasco Analítica Spain, S.L.).

Reference carotenoids were obtained from fresh green plants in J. Garrido's laboratory, as per Mínguez-Mosquera (1997). Known reference dilutions of zeaxanthin, lutein, and $\beta$-carotene were injected into the HPLC instrument to build a calibration curve at $450 \mathrm{~nm}$. The concentration of individual carotenoids was calculated from HPLC areas recorded at $450 \mathrm{~nm}$. The total carotenoid concentration $(\mu \mathrm{g} / \mathrm{ml})$ used in the analyses was obtained by adding together the values for zeaxanthin, lutein, $\beta$-carotene and other unidentified carotenoids for each individual.

\section{STATISTICAL ANALYSIS}

In this paper we aim to explore intraspecific and interspecific patterns of variation in plasma carotenoid concentrations in relation to parasite load and richness. Thus, the statistical relationships between carotenoids and parasites were tested using two different approaches.

Firstly, patterns of variation between individuals were analyzed by using generalized mixed-effect linear models. In this analysis, species was included as a random effect and the existence of a relationship between carotenoids and parasites was tested while allowing for species-specific differences in the intercept (but not the slope) between parasites and carotenoid concentrations (i.e., see Stamps et al., 2012). In preliminary analyses we included also random slopes in the models but the final models were fitted only with random intercepts because random slopes did not increase the fit of the models and complicated in some cases model convergence. In all the analyses sex (male or female), year (2004 or 2005), date of capture (days counted as from March 8) and time of capture (morning or afternoon) were included as fixed factors. The time of capture had an important effect on endoparasite abundance $\left[F_{(1,331)}=223.24, P<0.0001\right.$, see also López et al., 2007] and for this reason an interaction coding for time of capture and parasite abundance was included in the analyses that included intestinal parasites with significant diurnal cycles in egg shedding [coccidians: $F_{(1,331)}=338.63, P<0.0001$; Capilariida: $F_{(1,331)}=4.74, P=0.03 ; F_{(1,331)}<2.05, P>0.15$ for all other parasite groups]. The amount of variance explained by the species factor was estimated from changes in the model deviance.

Secondly, to investigate interspecific patterns of variation we first estimated for each variable and species the least-square means corrected for sex, time of capture, date, and year. Leastsquare means were then included in a generalized linear model to explore the covariates of plasma carotenoid concentration differences between species. In addition to parasites, the initial model included three other variables that are related to interspecific variation in carotenoid concentrations (Tella et al., 2004): mean body mass, the extent of carotenoid-derived coloration in plumage, and the extent of carotenoid-derived pigmentation in non-feathered parts (following the scoring methodology used by Tella et al., 2004). Phylogeny explains a relevant amount of variance in the concentration of circulating carotenoids (Tella et al., 2004), but most variance occurred at Order level and for this reason we restricted our analyses to passerine species.

In all the analyses carotenoid concentrations were considered to be the dependent variable and parasite richness (number of parasite taxons per individual) and parasite abundance as independent variables. Our results show that parasite abundance and richness are unrelated (see below) and consequently can be included both as independent variables without problems derived from colinearity. Carotenoid concentrations, parasite counts and mean body mass were log-transformed to attain normality. We followed a backwards selection procedure, starting with a model including all the variables (and in the case of intestinal parasites, its interaction with the factor "time of capture"), removing the least significant variable and fitting the model again until all the variables in the model contributed with $P<0.10$ to the fit of the model. Only variables with $P<0.05$ were interpreted as significant.

\section{RESULTS}

\section{RICHNESS AND ABUNDANCE OF INTESTINAL AND BLOOD PARASITES}

No relationship was found between the richness of intestinal and blood parasites in individuals $\left[r^{2}=0.01, F_{(1,330)}=0.04\right.$, $P=0.84$, Figure 1] or in species $\left[r^{2}=0.01, F_{(1,20)}=0.25, P=\right.$ $0.63]$. Likewise, intestinal and blood parasite abundances were unrelated at either level [inter-individuals: $r^{2}=0.00, F_{(1,330)}=$ $0.69, P=0.41$; inter-specific: $r^{2}=0.09, F_{(1,20)}=1.98$, $P=0.18]$.

\section{FACTORS RELATED TO CAROTENOID CIRCULATION}

In the analyses at individual level both year [larger concentrations in 2005 than in 2004, $F_{(1,330)}=18.26, P<0.0001$ ] and date [increases throughout the spring, $F_{(1,330)}=16.11, P<0.0001$ ] were related to carotenoid concentrations; no differences were found in carotenoid concentrations in relation to either sex $\left[F_{(1,329)}=0.24, P=0.62\right]$ or time of capture $\left[F_{(1,329)}=0.01\right.$, $P=0.92]$. Overall, species explained $42.78 \%$ of inter-individual variance carotenoid concentrations in plasma.

\section{ANALYSES OF THE RELATIONSHIPS BETWEEN PLASMA CAROTENOIDS AND PARASITISM AT INDIVIDUAL LEVEL}

Between individuals, plasma concentrations of carotenoids were negatively related to the richness of intestinal parasites $\left[-0.0767 \pm 0.0298, F_{(1,327)}=6.64, P=0.01\right.$, Figure $\left.2 \mathrm{~A}\right]$, but were not related to the richness of blood parasites or to the abundance of intestinal or blood parasites $\left[F_{(1,326)}<2.75, P>0.10\right.$ for all variables]. We repeated the analyses, taking into account separately coccidians and Spirurids, and also added data for the other parasite taxons with less than $5 \%$ prevalence in a group we named "other intestinal parasites." This second set of analyses confirmed the negative relationship between carotenoids and the presence of "other intestinal parasites" $\left[F_{(1,329)}=7.51\right.$, $P=0.007$, Figure 2B] and a trend for a negative relationship with the presence of Spirurids $\left[F_{(1,328)}=3.53, P=0.06\right]$. When we repeated the analyses with abundance, both "other intestinal parasites" and Spirurids were negatively related to carotenoid concentrations $\left[F_{(1,328)}=5.95, P=0.02\right.$, Figure 2C; $F_{(1,328)}=5.37, P=0.02$, Figure 2D]. Presence and abundance 


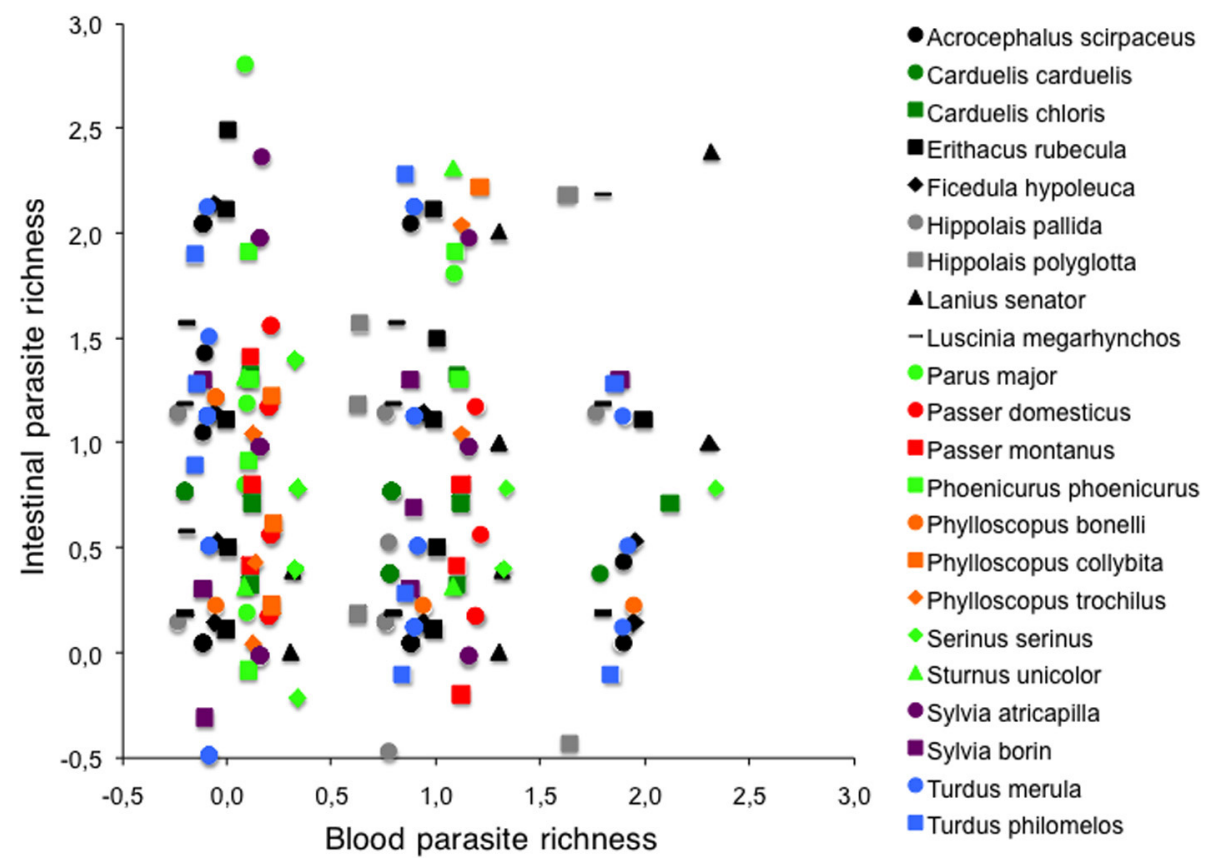

FIGURE 1 | Relationship between intestinal and blood parasite richness for 354 individual birds of 22 different passerine species after controlling for the effects of time of capture (morning or afternoon) on intestinal parasite richness. Species were included in the model as a random factor to allow different intercepts for data from different species but a common slope for all species. of coccideans were not related to carotenoid concentrations [prevalence: $F_{(1,328)}=1.24, P=0.27$; abundance: $F_{(1,327)}=$ $0.87, P=0.35]$.

\section{INTERSPECIFIC RELATIONSHIPS BETWEEN PLASMA CAROTENOIDS AND PARASITISM}

Both the proportion of carotenoids in the plumage $\left[0.0058 \pm 0.0019, F_{(1,17)}=9.87, P=0.006\right]$ and in nonfeathered parts $\left[0.0806 \pm 0.0323, F_{(1,17)}=6.21, P=0.02\right]$ were positively related to carotenoid concentrations. Carotenoid concentrations were unrelated to mean species body mass $\left[F_{(1,18)}=0.02, P=0.88\right]$. In addition, a negative relationship between carotenoid concentrations and the abundance of intestinal parasites was found $\left[-0.4925 \pm 0.2350, F_{(1,17)}=4.39\right.$, $P=0.05$, Figure 3]. This relationship was not due to the abundance of any particular intestinal parasite group [coccidians: $F_{(1,19)}=0.43, P=0.52$; Spirurids: $F_{(1,19)}=1.74, P=0.20$; other intestinal parasites: $F_{(1,19)}=0.05, P=0.83$ ]. No relationship between intestinal parasite richness $\left[F_{(1,17)}=3.19\right.$, $P=0.09]$, blood parasite richness or abundance was found $\left[F_{(1,18)}<0.08, P>0.78\right.$ for both variables $]$.

\section{DISCUSSION}

Traditionally, hypotheses concerning the relationships between host ecology and parasites have been tested by focusing on a particular group of parasites (e.g., Haematozoa, intestinal parasites, or ectoparasites). With this approach, the failure to falsify a hypothesis may be due to a lack of success in identifying the group of parasites that most significantly affect host fitness (unless the abundance of the different groups of parasites is highly correlated). Several studies have already pointed out that the intensity of infection by different species of parasites is not strongly correlated at intraspecific level (Møller, 1991; Weatherhead et al., 1993, but see Holmstad et al., 2008 for an exception). Our results indicate that species richness and abundance of blood and intestinal parasites are unrelated in analyses at both individual and species level. Consequently, conclusions obtained for one group of parasites cannot be extrapolated for the full community of parasites and so our capacity to rigorously test parasite-mediated selection hypotheses is lessened unless clear indications of the effects on host fitness exists for a significant fraction of the parasite community.

We believe that it is important to highlight that we did not analyze intestinal parasite fauna directly by killing and dissecting the birds. Rather, we used the release of parasite propagules in feces as a surrogate method for estimating intestinal parasite abundance and richness. Although this is not a direct measurement of parasite load, concentrations of parasite oocysts in feces do indicate parasite reproductive success (Chapman, 1998) in a highly reliable fashion (López et al., 2007). We cannot rule out the possibility that the correlation between blood and intestinal parasites was underestimated for these reasons. However, the relationships found between intestinal parasites and carotenoid concentrations suggest that we obtained biologically relevant estimates of the composition of intestinal parasite communities.

The second main result of our study is the finding of a negative correlation between intestinal parasite abundance or richness and carotenoid circulation in the blood. These relationships were detected between individuals (for intestinal parasite richness and the abundance of some intestinal parasite groups) and between 


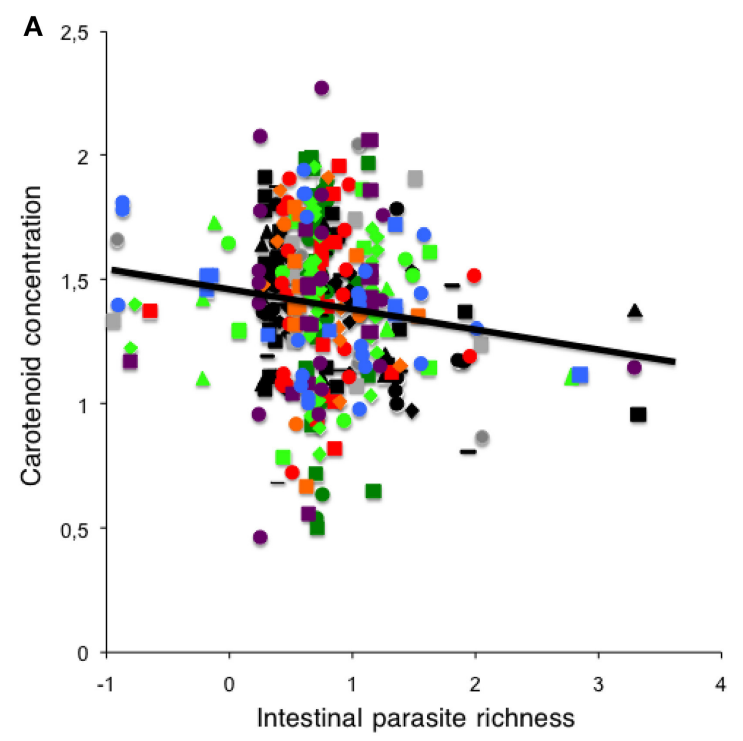

C

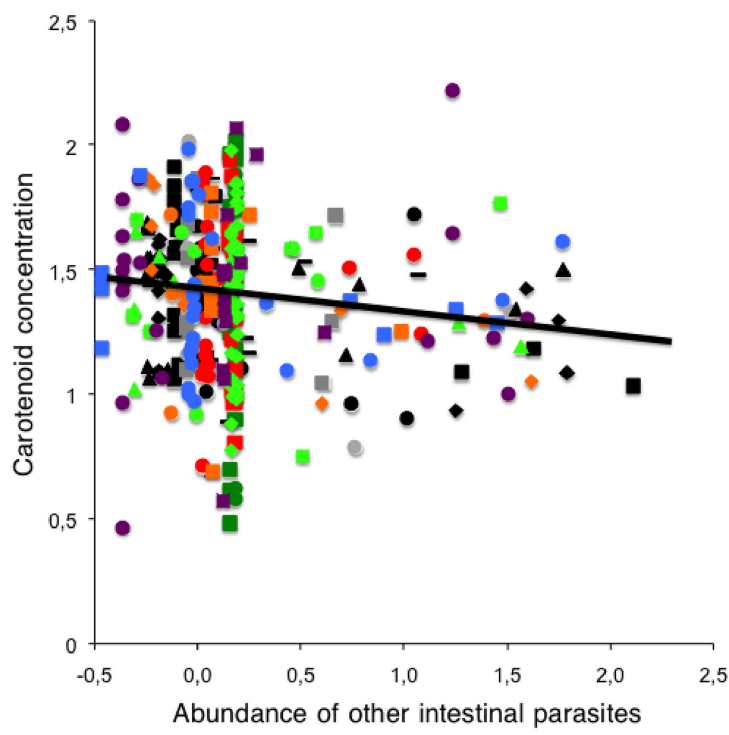

FIGURE 2 | Carotenoid concentrations and parasites. Relationship between carotenoid concentrations $(\mu \mathrm{g} / \mathrm{ml})$ in 354 individuals of 22 species of passerines and (A) intestinal parasite richness, $(\mathbf{B})$ prevalence of other

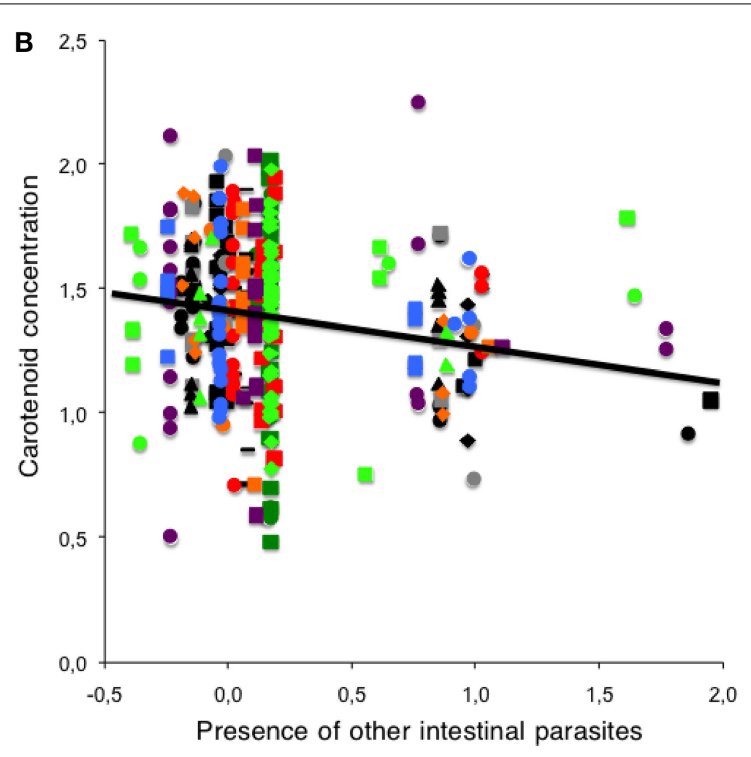

D

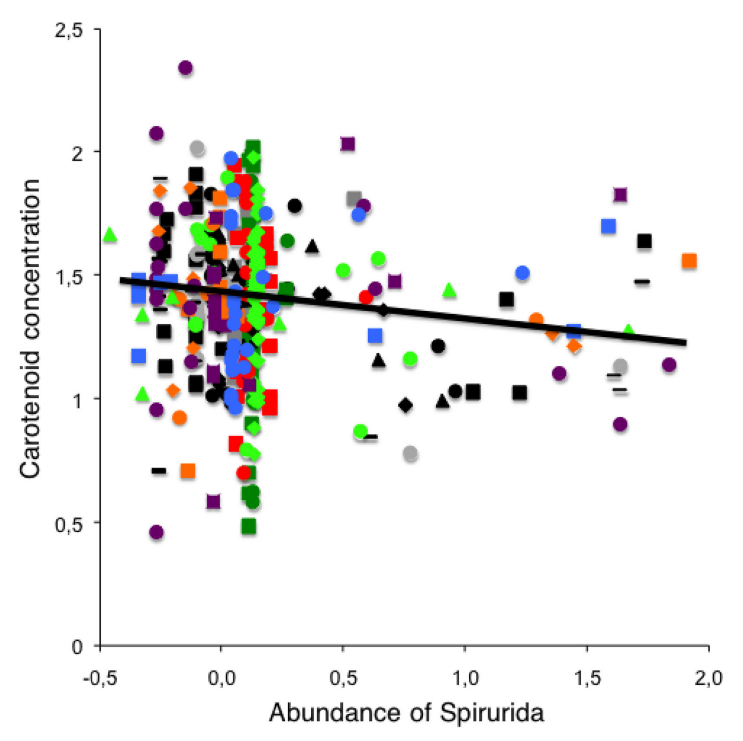

(less frequent) intestinal parasites, (C) abundance of other (less frequent) intestinal parasites and (D) abundance of the intestinal parasites of the Order Spirurida (see legend of Figure 1 to identify the data from each species). species (for the case of intestinal parasite abundance). There are several non-exclusive factors that can explain these results. Firstly, immune response to parasitism may require the mobilization of carotenoids as scavengers of free radicals released during an immune response, leading to the depletion of carotenoid stores and reduced carotenoid levels in the blood (Alonso-Alvarez et al., 2004; Pérez-Rodríguez et al., 2008, but see Constantini and Møller, 2008). However, in such a case we would expect a significant relationship between carotenoid concentration and overall parasite load and not only for intestinal parasites. Secondly, some intestinal parasites such as coccidians lessen carotenoid absorption in the intestines and thus reduce carotenoid incorporation into the blood (Ruff et al., 1974; Augustine and Ruff, 1983; Allen,
1987; Tyczkowski et al., 1991). Interestingly, we have found a negative relationship between infection by intestinal parasites and carotenoid concentration. These results support the hypothesis of an impact of parasites on carotenoid availability, for plumage coloration and other functions, through a negative effect on carotenoid uptake at the intestines. Thirdly, different kinds of parasites may differ in their overall impact on organisms health, and consequently on their impact on organisms oxidative stress. Unfortunately, no detailed information to test this hypothesis is available at this moment. Lastly, food (prey) that is poor in carotenoids may have been more parasitized, thereby exposing individuals and species to a higher amount of parasites. We suspect that this is not the case in our results given that 


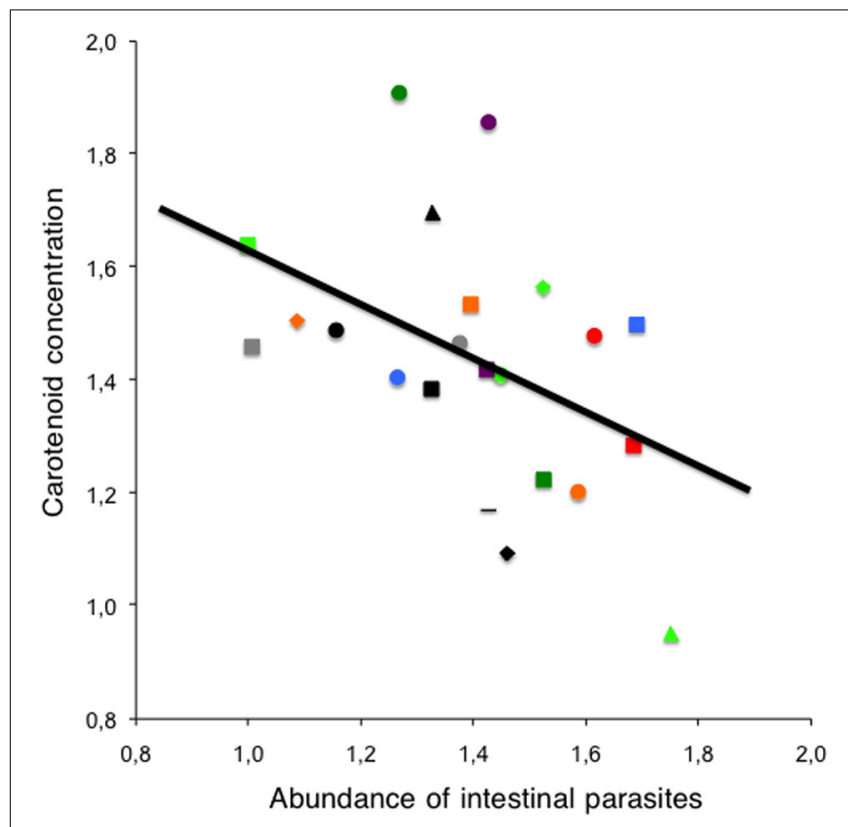

FIGURE 3 | Carotenoid concentrations and parasites. Relationship between the abundance of intestinal parasites and carotenoid concentrations $(\mu \mathrm{g} / \mathrm{ml}$ ) at interspecific level (see legend of Figure 1 to identify the data from each species).

previous analyses by Tella et al. (2004) failed to find any effect of diet on interspecific differences in carotenoid concentrations between species of the same family. However, a lack of information exists on how the consumption of carotenoid-rich foods is related to exposure to parasites at intra- and interspecific levels. We had found a negative relationship between carotenoid concentration and intestinal parasite richness. A similar negative effect for blood parasite richness and carotenoid derived coloration was reported for blue tits (Del Cerro et al., 2010). These effects of parasite richness may have at least two potential explanations: (1) the synergistic or accumulative effects of parasites and/or (2) an effect due to only one or just a few parasite taxons and consequently more likely to occur in an individual with a richer parasite fauna. We cannot differentiate between these two possibilities, although when we repeated the analyses separately for the different intestinal groups we found independent negative relationships for Spirurids and for the group "other nematodes." None of these groups of parasites is habitually the focus of studies of parasite evolution. In particular, Spirurida, an order of nematodes that use invertebrates as intermediate hosts, were associated with reduced levels of carotenoids in analyses at individual level. Our results suggest that it would be worthwhile to include this group of parasites in future analyses and experiments on the physiology of carotenoids and on the evolution of carotenoid-derived signals.

It is a little bit surprising that relationships between carotenoid concentration and intestinal parasite load has been found for two different groups of parasites but not for coccideans. The relationship between coccidians infection and carotenoid levels have been demonstrated in several studies (Zhu et al., 2000; Hõrak et al.,
2004; Pap et al., 2011). However, it is possible that the effects of the other groups of parasites on carotenoids is larger than for coccidians and had masked the results. It is also possible that the impact of coccidians (and any other of the groups of parasites studied) differs between species (see i.e., Coon et al., 2014) making difficult to detect significant correlations in comparative studies. Additionally, most of the samples in our study (69\%) were collected during the morning, while studies in passerines showed a strong time of day-effect for passage of oocystsm with the peak in late afternoon/evening (Brawner and Hill, 1999; López et al., 2007). Although we have controlled for time of day in our analyses, samples collected during the morning are less informative of coccidian loads.

In addition to intestinal parasites, two other variables were related to inter-individual variation in carotenoid concentrations in the blood: year and date of capture. Carotenoid concentrations were higher in 2005 than in 2004 and increased as spring progressed. As previously commented, carotenoids should be obtained from an animal's diet and in the case of birds both invertebrates and fruit are important sources of carotenoids. Both of these resources undergo significant annual and seasonal oscillations in abundance (Herrera et al., 1998; Jones et al., 2003) that may explain our results. Both the effects of year and season have been already reported in the case of the Great Tit Parus major, the only species in which seasonal and annual variation in plasma carotenoids has been studied to date (Isaksson et al., 2007). Our results confirm that these factors are applicable to the passerine communities present in our study area. Despite the fact that some studies have reported a higher concentration of carotenoids in males than in females during molting periods (Hill, 1995; Figuerola and Gutierrez, 1998), our results indicate that this is not the case during the spring, when no molting is occurring. Another potential reason for expecting sexual dimorphism in carotenoid circulation is the deposition of important quantities of carotenoids in eggs that may reduce female carotenoid stores (Saino et al., 2002; Royle et al., 2003). It is important to note, however, that the samples in our study were collected before the start of egg-laying in most of the species studied.

At interspecific level, the extent of carotenoid-derived coloration in feathers and skins was positively related to carotenoid concentrations in the blood, thus confirming the results reported by Tella et al. (2004). However, in contrast to this study, we failed to find any relationship between body mass and carotenoid concentrations, probably because of the smaller numbers and the lesser variation in body mass of the species analyzed in our study.

In conclusion, parasites are related to differences between individuals and species in the concentration of carotenoids in the plasma, suggesting that they may play an important role in the regulation of carotenoid levels. These effects are not generalized for parasites, but are specific to some groups. Interestingly, intestinal parasites had the potential to negatively affect the uptake of carotenoids at the intestines. Experimental studies are necessary to test the relevancy of reduced carotenoid uptake at the gut and/or the impact of these parasites on host health, oxidative stress and immune response to understand the range of impacts may have both on the accessibility and carotenoid needs of birds. Additionally, Spirurida were particularly related to reduced levels 
of carotenoids, suggesting that more attention should be paid to this group of parasites in future studies of host-parasite ecology.

\section{ACKNOWLEDGMENTS}

The capture and ringing of the birds was done under permits of the Spanish "Ministerio de Medio Ambiente." Blood sampling and research protocols were authorized by the Andalusian 'Consejería del Medio Ambiente'. Alberto Álvarez, Alicia Cortés, Ángel Mejía, Ara Villegas, Beatriz Fernández, Beatriz Sánchez, Carmen Gutiérrez, Chari Terceño, Cristina Sánchez, Elena Fierro, Enrique Sánchez, Esteban Serrano, Francisco Miranda, Grego Toral, Inma Cancio, Joaquín Díaz, José Antonio Sánchez, Mari Carmen Roque, Olga Jiménez, Pedro Sáez, Rafael Reina, Samuel del Río, Francisco Jamardo, Manuel Sánchez, Manuel Vázquez, Miguel Carrero, and Oscar González helped with fieldwork, ringing, bird handling and sample taking. The Spanish Ministry of Health via its Thematic Research Net "EVITAR" funded our research, which was also supported by the P.A.I. RNM118 and RNM014.

\section{REFERENCES}

Aguilera, E., and Amat, J. A. (2007). Carotenoids, immune response and the expression of sexual ornaments in male greenfinches (Carduelis chloris). Naturwissenschaften 94, 895-902. doi: 10.1007/s00114-0070268-5

Allen, P. C. (1987). Physiological responses of chicken gut tissue to coccidial infection - comparative effects of Eimeria acervulina and Eimeria mitis on mucosal mass, carotenoid content, and brush-border enzyme-activity. Poult. Sci. 66, 1306-1315. doi: 10.3382/ps.0661306

Alonso-Alvarez, C., Bertrand, S., Devevey, G., Gaillard, M., Prost, J., Faivre, B., et al. (2004). An experimental test of the dose-dependent effect of carotenoids and immune activation on sexual signals and antioxidant activity. Am. Nat. 164, 651-659. doi: 10.1086/424971

Augustine, P. C., and Ruff, M. D. (1983). Changes in carotenoid and vitamin A levels in young turkeys infected with Eimeria meleagrimitis or Eimeria adenoeides. Avian Dis. 27, 963-971. doi: 10.2307/1590197

Badyaev, A. V., and Hill, G. E. (2000). Evolution of sexual dichromatism: contribution of carotenoid- versus melanin-based coloration. Biol. J. Linnean Soc. 69, 153-172. doi: 10.1111/j.1095-8312.2000.tb01196.x

Bennett, G. F. (1970). Simple techniques for making avian blood smears. Can. J. Zool. 48, 585. doi: 10.1139/z70-098

Biard, C., Hardy, C., Motreuil, S., and Moreau, J. (2009). Dynamics of PHA-induced immune response and plasma carotenoids in birds: should we have a closer look? J. Exp. Biol. 212, 1336-1343. doi: 10.1242/jeb.028449

Blanco, G., Bautista, L. M., Hornero-Méndez, D., Lambertucci, S. A., Wiemeyer, G., Sanchez-Zapata, J. A., et al. (2014). Allometric deviations of plasma carotenoids in raptors. Ibis 156, 668-675. doi: 10.1111/ibi.12155

Blas, J., Perez-Rodriguez, L., Bortolotti, G. R., Viñuela, J., and Marchant, T. A. (2006). Testosterone increases bioavailability of carotenoids: insights into the honesty of sexual signalling. PNAS 103, 18633-18637. doi: 10.1073/pnas. 0609189103

Brawner, W. R., Hill, G. E., and Sundermann, C. A. (2000). Effects of coccidial and mycoplasmal infections on carotenoid-based plumage pigmentation in male House Finches. Auk 117, 952-963. doi: 10.1642/0004-8038(2000)117[0952: EOCAMI]2.0.CO;2

Brawner, W. R. III., and Hill, G. E. (1999). Temporal variation in shedding of coccidial oocysts: implications for sexual selection studies. Can. J. Zool. 77, 347-350. doi: 10.1139/z98-207

Carpenter, J. W. (1996). Avian and Exotic Parasitology. Philadelphia, PA: WB Saunders.

Chapman, H. D. (1998). Evaluation of the efficacy of anticoccidial drugs against Eimeria species in the fowl. Int. J. Parasitol. 28, 1141-1144. doi: 10.1016/S00207519(98)00024-1

Constantini, D., and Møller, A. P. (2008). Carotenoids are minor antioxidants for birds. Funct. Ecol. 22, 367-370. doi: 10.1111/j.1365-2435.2007.01366.x
Coon, C. A. C., Brace, A. J., McWilliams, S. R., McCue, M. D., and Martin, L. B. (2014). Introduced and native congeners use different resource allocation strategies to maintain performance during infection. Phys. Biochem. Zool. 87, 559-567. doi: 10.1086/676310

Del Cerro, S., Merino, S., Martínez de la Puente, J., Lobato, E., Ruiz de Castañeda, R., Rivero de Aguilar, J., et al. (2010). Carotenoid-based plumage colouration is associated with blood parasite richness and stress protein levels in blue tits (Cyanistes caeruleus). Oecologia 162, 825-835. doi: 10.1007/s00442-009-1510-y

Ellegren, H. (1996). First gene on the avian W chromosome (CHD) provides a tag for universal sexing of non-ratite birds. Proc. R. Soc. Lond. B 263, 1635-1641. doi: $10.1098 / \mathrm{rspb} .1996 .0239$

Figuerola, J., Domenech, J., and Senar, J. C. (2003). Plumage colour is related to ectosymbiont load during moult in the serin, Serinus serinus: an experimental study. Anim. Behav. 65, 551-557. doi: 10.1006/anbe.2003.2072

Figuerola, J., and Gutierrez, R. (1998). Sexual differences in levels of blood carotenoids in cirl buntings Emberiza cirlus. Ardea 86, 245-248.

Figuerola, J., Muñoz, E., Gutierrez, R., and Ferrer, D. (1999). Blood parasites, leucocytes and plumage brightness in the Cirl Bunting, Emberiza cirlus. Funct. Ecol. 13, 594-601.

Godfrey, R. D., Fedynich, A. M., and Pence, D. B. (1987). Quantification of Hematozoa in blood smears. J. Wildl. Dis. 23, 558-565. doi: 10.7589/0090-355823.4.558

Griffiths, R., Double, M. C., Orr, K., and Dawson, R. J. G. (1998). A DNA test to sex most birds. Mol. Ecol. 7, 1071-1075. doi: 10.1046/j.1365-294x.1998.00389.x

Hamilton, W. D., and Zuk, M. (1982). Heritable true fitness and bright birds - a role for parasites. Science 218, 384-387. doi: 10.1126/science.7123238

Herrera, C. M., Jordano, P., Guitián, J., and Traveset, A. (1998). Annual variability in seed production by woody plants and the masting concept: reassessment of principles and relationship to pollination and seed dispersal. Am. Nat. 152, 576-594. doi: 10.1086/286191

Hill, G. E. (1995). Seasonal variation in circulating carotenoid pigments in the House Finch. Auk 112, 1057-1061. doi: 10.2307/4089042

Hill, G. E. (2006). "Environmental regulation of ornamental coloration," in Bird Coloration: Function and Evolution, eds G. E. Hill and K. McGraw (Cambridge: Harvard University Press), 507-560.

Hill, G. E., and Johnson, J. D. (2012). The Vitamin A-Redox hypothesis: a biochemical basis for honest signaling via carotenoid pigmentation. Am. Nat. 180, E127-E150. doi: 10.1086/667861

Hill, G. E., and McGraw, K. J. (2006). Bird Coloration, Vol. 2. Cambridge, MA: Harvard University Press.

Holmstad, P. R., Jensen, K. H., and Skorping, A. (2008). Ectoparasite intensities are correlated with endoparasite infection loads in willow ptarmigan. Oikos 117, 515-520. doi: 10.1111/j.0030-1299.2008.16219.x

Hõrak, P., Saks, L., Karu, U., Ots, I., Surai, P. F., and McGraw, K. J. (2004). How coccidian parasites affect health and appearance of greenfinches. J. Anim. Ecol. 73, 935-947. doi: 10.1111/j.0021-8790.2004.00870.x

Isaksson, C., von Post, M., and Andersson, S. (2007). Sexual, seasonal, and environmental variation in plasma carotenoids in great tits, Parus major. Biol. J. Linnean Soc. 92, 521-527. doi: 10.1111/j.1095-8312.2007.00852.x

Jones, J., Doran, P. J., and Holmes, R. T. (2003). Climate and food synchronize regional forest bird abundances. Ecology 84, 3024-3032. doi: 10.1890/02-0639

López, G., Figuerola, J., and Soriguer, R. (2007). Time of day, age and feeding habits influence coccidian oocyst shedding in wild passerines. Int. J. Parasitol. 37, 559-564. doi: 10.1016/j.ijpara.2006.12.014

López, G., Jiménez-Clavero, M. A., Gómez-Tejedor, C., Soriguer, R., and Figuerola, J. (2008). Prevalence of West Nile virus neutralizing antibodies in Spain is related to birds' migratory behaviour. Vector Borne and Zoonotic Dis. 8, 615-621. doi: $10.1089 / \mathrm{vbz} .2007 .0200$

Martinez-Padilla, J., Mougeot, F., Perez-Rodriguez, L., and Bortolotti, G. R. (2007). Nematode parasites reduce carotenoid-based signalling in male red grouse. Biol. Lett. 3, 161-164. doi: 10.1098/rsbl.2006.0593

Mateos-Gonzalez, F., Hill, G., and Hood, W. (2014). Carotenoid coloration predicts escape performance in the House Finch (Haemorhous mexicanus). Auk 131, 275-281. doi: 10.1642/AUK-13-207.1

Mateos-Gonzalez, F., Quesada, J., and Senar, J. C. (2011). Sexy birds are superior at solving a foraging problem. Biol. Lett. 7, 668-669. doi: 10.1098/rsbl.2011.0163

McGraw, K. J., and Hill, G. E. (2000). Differential effects of endoparasitism on the expression of carotenoid- and melanin-based ornamental coloration. Proc. $R$. Soc. Lond. B 267, 1525-1531. doi: 10.1098/rspb.2000.1174 
Mínguez-Mosquera, M. I. (1997). Clorofilas y Carotenoides en Tecnología de Alimentos. Sevilla: Universidad de Sevilla.

Mínguez-Mosquera, M. I., and Hornero-Méndez, D. (1993). Separation and quantification of the carotenoid pigments in red peppers (Capsicum annuum L.), paprika and ole-oresin by reversed-phase HPLC. J. Agric. Food Chem. 41, 1616-1620. doi: 10.1021/ff00034a018

Møller, A. P. (1991). The Barn Swallow. Oxford: Oxford University Press.

Negro, J. J., and Garrido-Fernandez, J. (2000). Astaxanthin is the major carotenoid in tissues of white storks (Ciconia ciconia) feeding on introduced crayfish (Procambarus clarkii). Comp. Biochem. Physiol. B 126, 347-352. doi: 10.1016/S0305-0491(00)00180-2

Olson, V. A., and Owens, I. P. F. (1998). Costly sexual signals: are carotenoids rare, risky or required? Tree 13, 510-514. doi: 10.1016/S0169-5347(98) 01484-0

Pap, P. L., Vágási, C. I., Czirják, G. A., Titilincu, A., Pintea, A., Osváth, G., et al. (2011). The effect of coccidians on the condition and immune profile of molting house sparrows (Passer domesticus). Auk 128, 330-339. doi: 10.1525/auk.2011.10142

Pérez-Rodríguez, L., Mougeot, F., Alonso-Alvarez, C., Blas, J., Viñuela, J., and Bortolotti, G. R. (2008). Cell-mediated immune activation rapidly decreases plasma carotenoids but does not affect oxidative stress in red-legged partridges (Alectoris rufa). J. Exp. Biol. 211, 2155-2161. doi: 10.1242/jeb. 017178

Peters, A. (2007). Testosterone and carotenoids: an integrated view of tradeoffs between immunity and sexual signalling. Bioessays 29, 427-430. doi: 10.1002/bies.20563

Royle, N. J., Surai, P. F., and Hartley, I. R. (2003). The effect of variation in dietary intake on maternal deposition of antioxidants in Zebra Finch eggs. Funct. Ecol. 17, 472-481. doi: 10.1046/j.1365-2435.2003.00752.x

Ruff, M. D., Reid, W. M., and Johnson, J. K. (1974). Lowered blood carotenoid levels in chickens infected with coccidia. Poult. Sci. 53, 1801-1809. doi: 10.3382/ps.0531801

Saino, N., Bertacche, V., Ferrari, R. P., Martinelli, R., Møller, A. P., and Stradi, R. (2002). Carotenoid concentration in barn swallow eggs is influenced by laying order, maternal infection and paternal ornamentation. Proc. R. Soc. Lond. B 269, 1729-1733. doi: 10.1098/rspb.2002.2088

Scheuerlein, A., and Ricklefs, R. E. (2004). Prevalence of blood parasites in European passeriform birds. Proc. R. Soc. Lond. B 271, 1363-1370. doi: $10.1098 / \mathrm{rspb} .2004 .2726$

Simons, M. J. P., Cohen, A. A., and Verhulst, S. (2012). What does carotenoiddependent coloration tell? Plasma carotenoid level signals immunocompetence and oxidative stress state in birds - a meta-analysis. PLoS ONE 7:e43088. doi: 10.1371/journal.pone.0043088
Stamps, J. A., Briffa, M., and Biro, P. A. (2012). Unpredictable animals: individual differences in intraindividual variability (IIV). Anim. Behav. 83, 1325-1334. doi: 10.1016/j.anbehav.2012.02.017

Svensson, L. (1996). Guia Para la Identificación de los Passeriformes Europeos. Madrid: Sociedad Española de Ornitología.

Tella, J. L., Figuerola, J., Negro, J. J., Blanco, G., Rodriguez-Estrella, R., Forero, M. G., et al. (2004). Ecological, morphological and phylogenetic correlates of interspecific variation in plasma carotenoid concentration in birds. J. Evol. Biol. 17, 156-164. doi: 10.1046/j.1420-9101.2003.00634.x

Tyczkowski, J. K., Hamilton, P. B., and Ruff, M. D. (1991). Altered metabolism of carotenoids during pale-bird syndrome in chickens infected with Eimeria acervulina. Poult. Sci. 70, 2074-2081. doi: 10.3382/ps.0702074

von Schantz, T., Bensch, S., Grahn, M., Hasselquist, D., and Wittzell, H. (1999). Good genes, oxidative stress and condition-dependent sexual signals. Proc. $R$. Soc. Lond. B 266, 1-12. doi: 10.1098/rspb.1999.0597

Weatherhead, P. J., Metz, K. J., Bennett, G. F., and Irwin, R. E. (1993). Parasite faunas, testosterone and secondary sexual traits in male red-winged blackbirds. Behav. Ecol. Sociobiol. 33, 13-23. doi: 10.1007/BF00164342

Yang, C., Wang, J., and Sun, Y.-H. (2013). Is sexual ornamentation and honest signal of male quality in the Chinese Grouse (Tetrastes sewerzowi)? PLoS ONE 8:e82972. doi: 10.1371/journal.pone.0082972

Zhu, J. J., Lillehoj, H. S., Allen, P. C., Yun, C.-H., Pollock, D., Sadjadi, M., and Emara, M. G. (2000). Analysis of disease resistance-associated parameters in broiler chickens challenged with Eimeria maxima. Poult. Sci. 79, 619-625. doi: $10.1093 / \mathrm{ps} / 79.5 .619$

Conflict of Interest Statement: The authors declare that the research was conducted in the absence of any commercial or financial relationships that could be construed as a potential conflict of interest.

Received: 31 January 2014; accepted: 21 August 2014; published online: 12 August 2014.

Citation: Figuerola J, López G and Soriguer R (2014) Plasma carotenoid levels in passerines are related to infection by (some) parasites. Front. Ecol. Evol. 2:47. doi: 10.3389/fevo.2014.00047

This article was submitted to Behavioral and Evolutionary Ecology, a section of the journal Frontiers in Ecology and Evolution.

Copyright $\odot 2014$ Figuerola, López and Soriguer. This is an open-access article distributed under the terms of the Creative Commons Attribution License (CC BY). The use, distribution or reproduction in other forums is permitted, provided the original author(s) or licensor are credited and that the original publication in this journal is cited, in accordance with accepted academic practice. No use, distribution or reproduction is permitted which does not comply with these terms. 